\title{
Preparation of highly water dispersible functional graphene/silver nanocomposite for the detection of melamine
}

\begin{abstract}
A stable aqueous suspension of a functional graphene/silver (FG/Ag) nanocomposite was prepared by an environmentally friendly hydrothermal method. The precursor, functional graphene oxide (FGO), was prepared by covalent functionalisation of graphene oxide (GO) with a hydrophilic organosilane, $\mathrm{N}$-(trimethoxysilylpropyl) ethylenediaminetriacetic acid trisodium salt (TETA). The attachment of functional groups on the GO surface maintained the aqueous stability of the FG/Ag nanocomposite even after the hydrothermal reduction. Field emission scanning electron microscopy (FESEM) images illustrated a uniform distribution of $\mathrm{Ag}$ nanoparticles on the FG surface. The surface enhanced Raman spectroscopy (SERS) activity of the nanocomposite was investigated using paminothiophenol (p-ATP) and melamine which can be detected as low as $2 \times 10-8$ and $2 \times$ 10-7 M, respectively. The impressive water stability and the high SERS sensitivity of the FG/Ag nanocomposite make it a suitable substrate for trace analysis of a variety of drugs, additives or organic contaminants in water. The nanocomposite also showed a positive inhibition effect against the growth of Escherichia coli bacteria, eliminating the possibility of bacterial contamination of the sensor, thus prolonging the shelf-life of the sensing device.
\end{abstract}

Keyword: Nano composites; Nano particles; Raman spectroscopy; Graphene. 